This item was submitted to Loughborough's Research Repository by the author.

Items in Figshare are protected by copyright, with all rights reserved, unless otherwise indicated.

\title{
Towards industrial internet of things: crankshaft monitoring, traceability and tracking using RFID
}

PLEASE CITE THE PUBLISHED VERSION

http://dx.doi.org/10.1016/j.rcim.2016.02.004

PUBLISHER

(C) Elsevier

VERSION

AM (Accepted Manuscript)

\section{PUBLISHER STATEMENT}

This work is made available according to the conditions of the Creative Commons Attribution-NonCommercialNoDerivatives 4.0 International (CC BY-NC-ND 4.0) licence. Full details of this licence are available at: https://creativecommons.org/licenses/by-nc-nd/4.0/

\section{LICENCE}

CC BY-NC-ND 4.0

\section{REPOSITORY RECORD}

Segura-Velandia, Diana M., Navjot Kaur, Paul Conway, William Whittow, and Andrew West. 2016. "Towards Industrial Internet of Things: Crankshaft Monitoring, Traceability and Tracking Using RFID". Loughborough University. https://hdl.handle.net/2134/20726. 


\title{
Towards Industrial Internet of Things: Crankshaft Monitoring, Traceability and Tracking Using RFID
}

\author{
Diana M. Segura Velandia ${ }^{1}$, Navjot Kaur ${ }^{1}$, Paul P. Conway ${ }^{1}$, William G. Whittow ${ }^{2}$ and Andrew A. \\ West $^{1}$ \\ ${ }^{1}$ Wolfson School of Mechanical and Manufacturing Engineering and ${ }^{2}$ Department of Electronic and Electrical Engineering, Loughborough \\ University, England, UK
}

\begin{abstract}
The large number of requirements and opportunities for automatic identification in manufacturing domains such as automotive and electronics has accelerated the demand for item-level tracking using radio-frequency identification technology. End-users are interested in implementing automatic identification systems, which are capable of ensuring full component process history, traceability and tracking preventing costly downtime to rectify processing defects and product recalls. The research outlined in this paper investigates the feasibility of implementing an RFID system for the manufacturing and assembly of crankshafts. The proposed solution involves the attachment of bolts with embedded RFID functionality by fitting a reader antenna reader to an overhead gantry that spans the production line and reads and writes production data to the tags. The manufacturing, assembly and service data captured through RFID tags and stored on a local server, could further be integrated with higher-level business applications facilitating seamless integration within the factory.

Index Terms-Internet of Things, RFID, Automotive Applications
\end{abstract}

\section{INTRODUCTION}

$\mathrm{M}$ anufacturers have already started investing in hardware, software, and networking systems across the world and developing strategies to build the Internet of Things (IoT) and Services architecture to capitalise upon its benefits. The German government describes this strategy as the next industrial revolution under the heading of Industrie 4.0 [1]. In the US, a similar initiative to make factories smarter is known the Smart Manufacturing Leadership Coalition [2]. Other industrial initiatives also exist aiming at bringing recent advances in mobile computing, sensors, IoT, services and communications to the shop floor [3].

Smart industries include global intelligent networks made of Cyber-Physical Systems (CPS), , which combine physical systems and information communication technology [4]. These systems can control each other autonomously to predict failures, trigger maintenance processes autonomously, provide advanced analytics or trigger selforganised logistics to respond to changes in the production [5].

In order to become smart, manufacturing companies need to employ new intelligent methods of production and target a marketplace in which real time information is exchanged between products and machine services. Intelligence is made possible by embedding processors, sensors, and transmitters in any type of physical object (e.g. machine, product, material), as well as by developing software systems for structuring data flows. Also by creating a digital identity, a product that is in the process of being manufactured, can carry its digital memory throughout its life cycle and can communicate with its environment.

Fig. 1 shows an example of smart CPS in the automotive domain where software interfaces and services support interoperability between physical and control structures, hence, enabling smooth data transfer from and to the virtual and physical worlds.

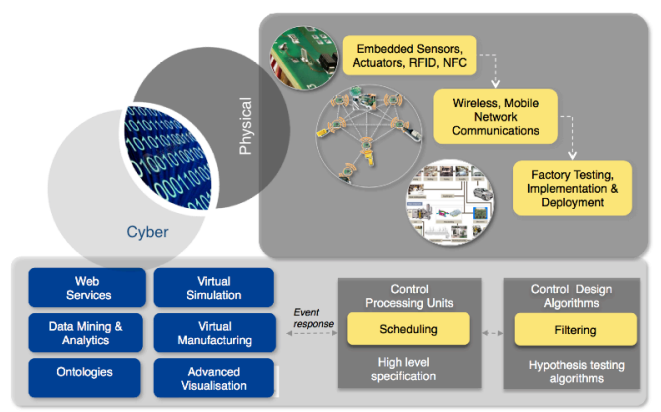

Fig. 1 Cyber-physical systems in Automotive Manufacturing.

The case study presented in this paper provides an original contribution to both researchers and practitioners. First attempt to fill the existing lack of evaluation of industrial implementations of RFID for full part genealogy and process history throughout manufacturing and engine assembly processes. Second, to support stakeholders who are evaluating whether to adopt RFID technology in their organisations.

The contribution of this research has a relevant practicality, as it helps decision makers to address their decisions in adopting RFID in comparison with other technologies, and on objective evaluations in industrial environments.

This paper aims at first, to compare current technologies for tracking parts within the automotive domain and to understand their disadvantages when used throughout manufacturing and engine assembly processes; second, to 
test the different RFID systems (tags, hardware architecture and software), which can be adopted to tag crankshafts and similar engine components to address the aforementioned challenges and third, to discuss the expected financial implications associated with adopting RFID for tagging crankshafts.

A description of crankshaft manufacturing is presented in in Section II followed by the state of the art in current available technologies for tracking engine parts within the automotive industry. The proposed RFID system architecture for crankshaft tagging is presented in Section III. The experimental and simulation results from designing both low cost UHF passive RFID tag and an optimised reader antenna infrastructure that can deliver reliable reading rates in metal environments are presented in Sections IV and $\mathrm{V}$ respectively. A discussion of the challenges and benefits, associated to the proposed RFID tagging options for crankshafts is presented in Section V. Finally, concluding remarks are presented in Section VI.

\section{StATE OF THE ART}

\section{A. Crankshaft Manufacturing Process Overview}

In the automotive industry a large number of engine components are manufactured in-house. For example, some automotive Original Equipment Manufacturers (OEMs) manufacture only 5Cs i.e. Cylinder block, Cylinder head, Crankshaft, Camshaft, and Connecting rod in-house and procure all other components from suppliers. Other OEMs prefer to reduce these numbers to 3Cs i.e. Cylinder block, Cylinder head, Crankshaft, depending on the availability and reliability of the supply chain and concentrating only on highly value-added, critical, high-technology operations that require high capital investment.

\section{1) Crankshaft manufacturing processes}

Crankshafts are machined through a sequence of automated operations that remove material using lathes and milling machines. Other off-the line processes include inspection, test and repair. As shown in Fig. 2, the manufacturing of crankshaft starts by manually loading rough castings of crankshafts into the manufacturing line. Then, various milling operations (which can be split into roughing and finishing) are performed onto crank pins, main bearing journals, web shapes and flange diameters [6].

Crankshaft processing modes can be achieved by either sequential line or parallel manufacturing operations, depending on production demands. Because of the parallelism, even if any of the machines within the system fails, there is no need to stop the entire system leading to increased reliability and efficiency. However, without being able to identify the exact manufacturing path that each part has followed, manufacturers with highly automated, parallel manufacturing processes are challenged with effective ways of monitoring, tracing and controlling quality problems introduced by every machine in real-time.

Crankshaft processing does not permit the product to be palletised, i.e. using a structure to support it while being handled during its manufacture. This is due to the rotating machining processes employed and the number of unique process technologies required. Therefore, there is a need to track each product during their manufacturing and assembly processes.

Current data marking techniques include etching a 2D data matrix on the part based monitoring these components through the process using camera based readers [7]. However, the collection of process history for crankshaft machining and assembly has not been successful to date using 2D data matrix codes or other tracking technologies. This is the case due to the harsh operating conditions of the processes, the need to machine a large number of the surfaces that could be used to etch the matrix onto the part and the difficulty of aligning readers and parts and the relative high cost of camera based systems.

\section{B. Automotive Component Part Tracking}

\section{1) Direct part marking}

Currently, Direct Part Marking (DPM) is the preferred method for tracking parts throughout their lifecycles for the automotive and aerospace industry [7]. DPM is a process by which bar codes are permanently marked onto a variety of materials [8]. The most common barcode symbology to use with DPM is a 2 dimensional (2D) bar code or DataMatrix. Specifically, in the ECC 200 version of DataMatrix (which has the error correction schema (ECC) with Reed-Solomon codes), data are encoded in several areas to allow for correct decoding even when parts of this area are distorted or covered [9], ECC 200 has hence been adopted as an automotive industry standard codified by AIAG (Automotive Industry Action Group) [10]. Some examples of organisations that use 2D Data Matrix codes include BMW, Ford Motor Company [11], NASA, PSA (PeugeotCitroen), Pratt \& Whitney, Airbus, Deutsche Post, Boeing, Pfizer and the United States Postal Service [9].

\section{2) Tracking of cranks using $2 D$ matrix}

Automotive parts monitored through their processing using matrix codes include engine components such as crankshafts, cylinder heads and blocks [12] and also fuel injectors. Automotive manufacturers encode different information depending on the part. For example, the 2D matrix for crankshafts contains production-related data, such as type, date and batch information and bearing grades to be used in selective assembly [12]. Similarly, injectors encode, in the 2D matrix, values such as the trim data set [13]. During assembly into the engine, the 2D code is scanned (by either a human operator or by an automated scanning system) and uploaded into the engine control unit (ECU) where the trim information is used to correct the injections [14].

\section{3) $2 D$ code crankshaft information}

The use of DataMatrix codes is integrated as part of the manufacturing process rather than being a secondary or manual process. Therefore, machine vision systems (hardware and software) are installed on automated production lines to read DataMatrix codes. Reading rates for camera systems are of up to 30 parts per second. As shown in Fig. 2 crankshafts may receive their data matrix 
encryption at the start of the production process, where the birth history information (i.e. serial number, date and engine derivative) is encoded using a laser, which generally produces the fastest marking cycle. Also, the bearing grades information may be encoded at the end of the machining processes to be used in engine assembly processes.

\section{1) 2D DataMatrix memory capacity}

The amount of data that can be encoded in a DataMatrix 2D code depends on the size of the symbol used and varies depending on the type of data (e.g. numeric, character), the encoding mode (e.g. ASCII, C40, text) and what the scanner can read. In addition, most camera based imagers and handheld scanners efficiencies decrease when reading symbols containing over 800 characters and switching between different types of characters, such as reading between numbers, upper case, lower case and punctuation. Although the DataMatrix specifications for maximum encoding capacity of a ECC-200 symbol (used in automotive) state 1556 8-bit ASCII characters or 3116 numerical digits or 2335 alpha numeric characters in the largest $144 \times 144$ (row x column) symbol [9], it has been determined that the best scenario is to encode up to 1200 ASCII characters. Industrial implementations use an $8 \times 8$ symbol for marking crankshafts.

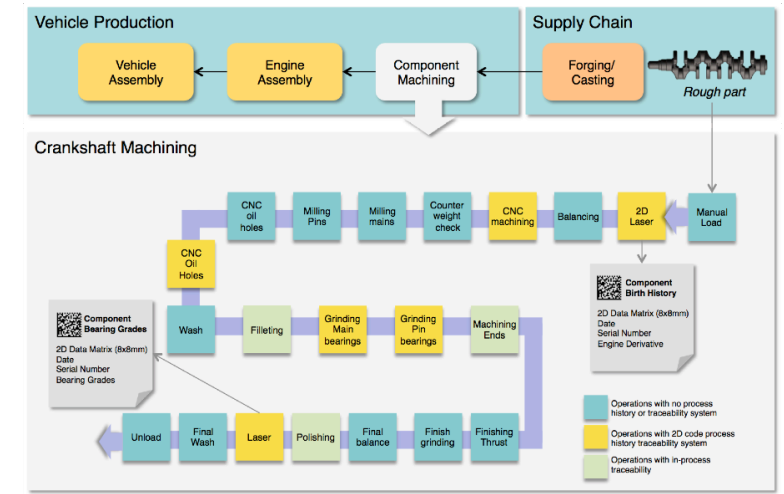

Fig. 2 Crankshaft manufacturing operations. Only a small number of machining operations can be traced using $2 \mathrm{D}$ symbols. The machine history is not marked on the component but stored on a server.

\section{2) 2D DataMatrix symbol drawbacks}

If good reading access across the production line is feasible, it is possible to position cameras to scan the $2 \mathrm{D}$ code to read for example, its serial number and then record which operations the product has passed through. As an example shown in Fig. 2, at the $\mathrm{CNC}$ and grinding machining operations (highlighted in yellow) cameras could read the $2 \mathrm{D}$ code and upload the machine history data to a server. However, it is not economically and sometimes technically feasible to place 2D scanners at key or all of the machining operations, hence, it is not possible to obtain a full process history and complete component traceability for machined parts. Currently, this is one of the major drawbacks in the use of 2D DataMatrix technology for tracking and monitoring crankshafts during the machining and assembly processes.

\section{3) 2D DataMatrix vision system challenges}

DataMatrix systems have many advantages for identification and traceability of engine components. They enable product genealogy to be supported capturing historical production information after changes are made, real time product knowledge and control, defect tracking and integration into enterprise software systems. However, these systems also present challenges to manufacturers, which can contribute to significant cost overruns, schedule delays and reduced system reliability. The most common problems are related to difficulties reading the $2 \mathrm{D}$ code due to errors in code printing and also surface contamination, water and humidity and varying lighting levels, which affect the code recognition. Novel decoding algorithms [15] and optical hardware integrated with machine vision advances address reflection and illumination problems [16]. However, poor system accessibility, operability and maintenance remain a problem for $2 \mathrm{D}$ system deployment in automated parallel manufacturing systems. Due to the impracticality of positioning $2 \mathrm{D}$ recognitions systems for each operation, full component's traceability and process history cannot be achieved.

\section{RFID for parts tracking}

RFID technology has also been considered to address the automotive industry challenges related to part identification, traceability and monitoring within OEM's flexible manufacturing and assembly plants and across the product supply chain.

RFID is the wireless use of radio-frequency electromagnetic fields to transfer data using "tags" attached to objects. These tags contain electronically stored information. Some tags are powered by and read at short ranges (a few metres) via magnetic fields (electromagnetic induction). Others use a local power source such as a battery and may operate at hundreds of meters. Unlike a barcode, the tag does not necessarily need to be within line of sight of the reader and may be embedded in the tracked object.

Most RFID systems reported in the literature have a generic architecture comprised of three main components. First, RFID readers or reading points are located throughout the production line configured to read data from RFID tags affixed to parts, wherein each RFID tag uniquely identifies a part. Then, a data processing system is configured to process the data collected by the RFID reader and a service application is developed to provide tracking and traceability information to end users.

\section{1) RFID Reader Points}

RFID readers can be installed at various locations in the production line. Some of these locations are stationary mounting locations. Examples include RFID readers installed on a bracket or post located adjacent to a conveyor belt or as a gate or portal. Other locations are mobile mounting locations, such as that of an RFID reader installed on a forklift $[17,18]$, or attached to a gantry robot as proposed in this paper. All these geographically dispersed RFID readers can be interconnected either wired or wirelessly producing a distributed RFID system or grid with 
the aim to detect, identify, write process information and track moving tagged parts in the manufacturing and assembly lines.

\section{2) RFID Tags to metal parts}

Affixing RFID tags to metal parts such as engine parts can be challenging as metallic objects strongly affect the performance of the antenna (e.g. radiation efficiency, gain) [19]. Some RFID systems for tagging engine parts have proposed the use of smart bolts, which have an embedded passive RFID tag in the recessed surface of the bolt's head [20]. Other passive tags can be affixed to the metallic objects using mechanical fasteners or glued with epoxy or high temperature resistance adhesives [21] (see to Fig. 3).

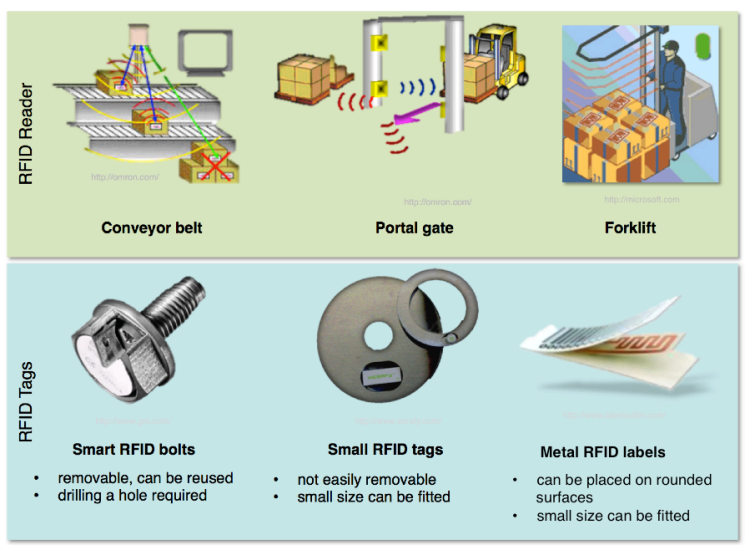

Fig. 3. Common mounting locations for RFID readers and RFID tags used for metallic parts.

\section{3) Use of RFID bolts for tracking engine components}

General Motors developed a smart bolt attached directly to cylinder heads and engine blocks to collect data during manufacturing [22]. The reported RFID bolt can store up to $2 \mathrm{kB}$ of data about the production line recorded throughout 50 different RFID reader points. At each machining process, the RFID reader reads part data stored in the bolt to check any previous process and writes new information onto the RFID bolt once the machining process has completed. This information enables any out-of-spec engine block or cylinder head to be removed off the line to be inspected by a worker and reworked if possible.

\section{4) RFID Memory capacity}

Similarly to 2D DataMatrix, the potential of RFID, goes beyond the simple identification of objects. Because of its enhanced data storage capabilities, RFID tags can be used as a means of decentralised data storage [23, 24]. While object identification uses a unique global identification attribute called Electronic Product Code (EPC), the RFID tags come with additional user memory (i.e. Electrically Erasable Programmable Read-Only Memory (EEPROM)) ranging from 256 bits up to $64 \mathrm{kB}$ [25]. Using this high memory capacity, more data can be stored on the tag with lesser reliance on a centralised network database. This approach is known as a data-on-tag approach [24]. This means that unlike the 2D Data matrix, the complete machining and process history can be recorded on tagged components as well as stored on a local or remote database server.

\section{5) Use of RFID tag data}

Data-on-tag is a decentralised way of storing data into the tag and can be accessed at different distribution points without a network connection. This method is also used to avoid bottlenecks at the central database. As an example, data from processes such as e.g. production control and maintenance, which cannot be disrupted even if there is a network failure, are stored on-tag. Other process information saved on-tag may include location history (e.g. last seen date), historical data from processing and testing (e.g. accept/reject), repair, and off-line operations data.

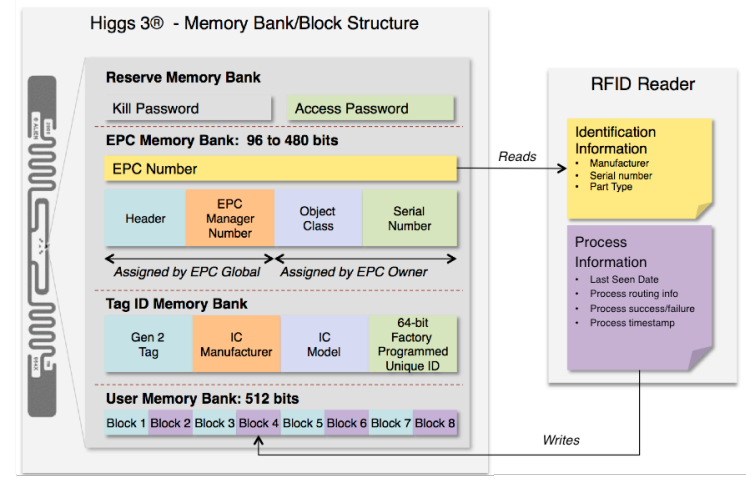

Fig. 4. Memory structure example for Higgs 3 IC.

\section{6) RFID data storage methods}

In contrast, the Data-on-network approach requires a secure network setup with middleware to filter data from the RFID readers before storing data into a central database. Once in the server, object related data are referenced using the EPC and then further object information is queried by a web service application [24].

As shown in Fig. 4 identification information and process information data are read and written by the RFID reader to various memory banks within the tag. The EPC Memory Bank, encodes identity information. For the given example in Fig. 4 the UHF RFID Tag IC corresponds to a Higgs 3. This chip conforms to the EPC global Class 1 Gen 2 specifications [26]. This standard suggests an encoding scheme for the EPC number i.e. the General Identifier (GID96), which is composed of the following fields: header, EPC manager number, object class and serial number. The EPC global user memory bank provides a variable size memory to store additional data attributes such as the process information related to the object identified in the EPC.

Unlike DataMatrix 2D codes, Data-on-tag, along with other real-time production data can be used to improve production control. Using an RFID infrastructure that enables reading and writing process information within a machining process cycle time, enables parts to be quarantined if they are manufactured outside of the specified tolerances due to e.g. tool wear or errors. This action may help prevent damage caused to factory equipment hence improving tool life and delaying machine maintenance, which can be prohibitively high.

7) RFID adoption in the automotive industry

Although RFID has been adopted by leading automotive 
and aerospace companies to identify and track engine parts and improve their production and logistic processes throughout their supply chain, there is still some reluctance to fully adopt RFID as the unique solution for part identification and tracking. This is partly due to many strategic and operational challenges of implementing RFID [27-29].

Key operational challenges for the industrial deployments RFID systems addressed in this paper include, first, designing both low cost UHF passive RFID tags and optimised reader antenna infrastructures that can deliver reliable reading rates in heavy-metal environments. Second, integrating the RFID system to existing technologies to the shop floor (such as machines, IT systems and other part tracking technologies). Third, assessing the business value that RFID brings to a company.

The main technical challenge in implementing RFID for tracking engine parts throughout production and assembly is that any proposed RFID system has to operate efficiently around metal and within a harsh operating environment that is typical of automotive manufacturing. Affixing RFID tags to metals can make their response unpredictable. RFID tag's responses are related to the maximum distance allowed between the reader and the RFID tags that results in reliable reading performance. Electromagnetic modelling of the system under investigation (i.e. Crankshaft and RFID tag) has been employed to simulate performance and engineer the optimal tag antenna and mounting substrate.

Successful industrial deployment of RFID systems requires industrially accepted both hardware and software architectures to support interfaces to typically PLCcontrolled machinery and to interact with existing company systems such as ERP, quality, MES, PLMs systems in near real-time. In this research, a scalable component-based and service-oriented software system was developed, adhering to industry and vendor-neutral standards based on industrially specified architectures and languages [30].

In addition, in complex supply chain RFID implementations, an RFID infrastructure must support and protect data owned by different business partners [31]. Therefore, data security is a critical issue that must be addressed from both technical and business perspectives.

The business benefits of using RFID are well known [3235], however it maybe difficult for companies to quantify the benefits and costs associated with adopting RFID. Several researchers have examined the different variables associated with RFID technology adoption [28, 29, 36]. However, it is difficult for a company to visualise potential pitfalls of optimal system design, performance limitations and system integration issues, essential to ensure reliable deployment.

Testing of commercial off-the shelf products in conditions close to the operational scenario can provide valuable assistance to decision makers and RFID designers on a wide range of implementation issues as well as evaluation of overall system performance [37]. This paper presents results of testing on-metal RFID tags that have been proposed as suitable for usage on crankshafts.

\section{PROPOSED RFID SYSTEM ARCHITECTURE}

\section{A. RFID system hardware architecture}

For the monitoring, traceability and tracking of crankshafts throughout the relevant machining and assembly processes, the design depicted in Fig. 5, was proposed. The system consists of an integrated antenna reader (i.e. transmitter and receiver), which is held by a bracket to the gantry gripper and bolt transponders affixed to the crankshaft. Depending on the antenna reader chosen, typical power outputs are normally 1 watt, frequency ranges of 886$928 \mathrm{MHz}$ (EU-US) and read/write ranges of $6 \mathrm{~cm}$ to $3 \mathrm{~m}$ with a cone cover area of about $70^{\circ}$ (refer to section $\mathrm{V}$ ).

The gantry robot is programmed with the complete process routing of the crank, enabling an embedded RFID tag attached to each crankshaft to be used to record the complete process history. Since the gantry robot is used as a common transfer element for all of the manufacture operations, this option, addresses the process gaps left by other tracking systems such as DataMatrix, which can only collect limited process history information since recordings are made only at a small number of discrete points within the process.

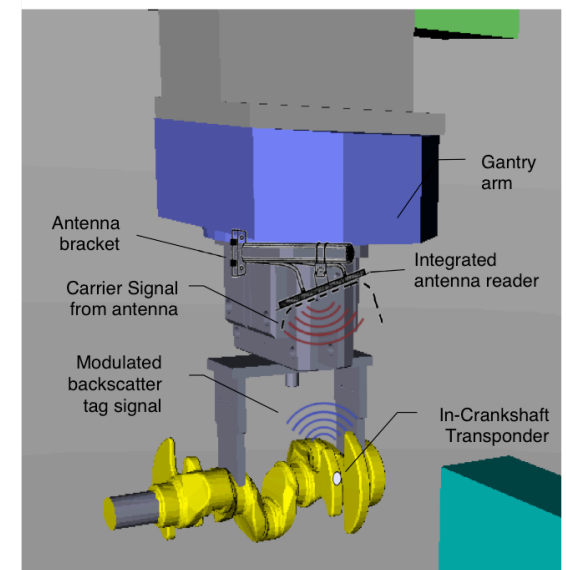

Fig. 5. Proposed RFID System for Crankshaft Monitoring.

Multiple portal based RFID systems can have limitations since a complete process history is not possible unless each machine is fitted with a reading portal, which can increase deployment costs. Also maintenance costs are increased if more portals are added.

The proposed transfer component architecture is applicable in any industrial environment where goods transfer between operations is required. Using the gantry option, integration with the robot control system is required to extend RFID system functionality, for example, to remove parts from the production line during machining problems or other process alerts.

\section{B. RFID system software architecture}

Additional processes have to be implemented to attach RFID tags to a crankshaft. When a part enters or leaves any process, RFID tags are interrogated and the corresponding processes identities are automatically stored and streamed to 
a remote database as time-ordered records. These records are stored in the form of an EPC number, location and time, plus any process information, when and where detection took place.

\section{METHOD}

\section{A. UHF Passive Tag Selection}

When formulating an RFID solution, several aspects, which cannot be considered in isolation, need to be defined.

\section{1) Operation frequency}

There has been a lot of debate as to whether to use HF or UHF for item level tagging [38]. For both frequencies, the RF waves interact with physical objects differently. Some researchers have claimed that HF performs better around water and metal, and the read field is easier to define than with UHF [39]. However, UHF radio waves can reflect off objects further away, causing a reader to detect tags outside the reading field.

\section{2) Tag location}

The best location to affix RFID tags to an object has to be determined in order to optimise communication performance with the reader (i.e. read rate, RSSI) and assess how reading performance changes with different locations. Two locations in the crankshaft were evaluated, the flywheel attachment surface and the middle counterweight surface (see Fig. 6).

\section{3) Tag selection}

Different RFID tag mounting locations on metallic surfaces result in changes such as frequency shift, bandwidth reduction and far-field degradation [40]. All of these parameters affect the readability of a tag by the reader antenna. Evaluating the performance of different tag locations requires various antenna topologies to be considered at the same time. Each antenna topology has a radiation pattern that will perform better at certain locations and orientations. Linearly polarised bolt tags were used for the crankshaft tagging. The tags were mounted so that the reader antenna and tags were aligned on the same vertical axis to provide maximum signal strength response (see results in section V). The vendor's data sheet states that the maximum reading distance when attached to metal is $2 \mathrm{~m}$ [41]. However, this value was verified experimentally with the proposed crankshaft and manufacturing process conditions representative the industrial environment as closely as possible.

\section{4) Tag packaging}

The robustness of the physical tag embodiment and packaging has to be determined tag robustness for the system under study. As the application requirements are demanding (e.g. metallic environment, high temperature, high humidity), the engineering of suitable RFID tags such as the choice of material substrates and protective packaging become more complex.

\section{5) IC interconnection}

RFID tags comprise an integrated circuit (IC) and a metallic antenna (e.g. aluminium, copper or silver) [42]. The antenna is commonly attached internally to the IC microchip. The interconnection between the IC and the antenna (e.g. wire bond, TCP (tape carrier package), flip chip) is of paramount importance and its quality strongly affects the tag's read range i.e. the maximum distance at which the RFID reader can detect the backscattered response from the tag [43]. A poor interconnection can result in degradation in the power transfer from tag antenna to IC thus impairing the tag performance and read range [43].

For retail RFID applications, label tags are used. These tags are essentially inlays (i.e. IC and antenna bonded to a paper or polyethylene terephthalate (PET) layer). To make a smart label, inlays are adhered to a label then printed and encoded in an RFID printer. However, for harsher applications, label tags are not durable and will not work or will perform sub-optimally when placed directly onto metallic surfaces. Therefore, inlays may have a stand-off material such as plastic or foam that separates the inlay from the metal. Alternatively, the tag antenna is directly printed onto a high permittivity material to make it capable of operation on metal [44].

In addition, inlays can be further packaged, encapsulated or embedded using different materials and designs. Most common designs include bolts, screws and sandwich layers of materials, which are engineered to perform well on metal although they can increase the cost of the final tag up.

A number of commercial off-the-shelf UHF passive tags were pre-selected (Table I) to evaluate their performance for tagging crankshafts. The read range and signal strength were measured in a laboratory environment with multiple metal objects in close proximity to provide an accurate representation of the industrial environment.

TABLE I. UHF PASSIVE RFID TAGS TESTED ON CRANKSHAFT

\begin{tabular}{|c|c|c|c|}
\hline UHF Passive Tag & $\begin{array}{c}\text { Affixing } \\
\text { options }\end{array}$ & $\operatorname{Tag} \operatorname{Cost}^{\mathrm{a}}$ & $\mathrm{Size}^{\mathrm{b}, \mathrm{c}}$ \\
\hline X-Dot-in & Adhesive & $£ 3.4$ & $\varnothing 6 \times 2.5$ \\
\hline Rino & Adhesive & $£ 0.5$ & $14 \times 38 \times 3.4$ \\
\hline Pro mass & $\begin{array}{l}\text { Rivet hole; } \\
\text { Inset }\end{array}$ & $£ 3.0$ & $50 \times 50 \times 5$ \\
\hline R-Bolt M12 & $\begin{array}{l}\text { Screw } \\
\text { thread }\end{array}$ & $£ 3.2$ & $\varnothing 12$ \\
\hline X-Bolt M8 & $\begin{array}{l}\text { Screw } \\
\text { thread }\end{array}$ & $£ 6$ & $\varnothing 8$ \\
\hline U-Chip $^{\mathrm{d}}$ & Adhesive & $£ 0.25$ & $2.5 \times 2.5 \times 0.4$ \\
\hline
\end{tabular}

From the pre-selected tags, three options for mounting or affixing the tags to the crankshaft were considered. First, using a high performance adhesive. Second, riveting in a hole or inset previously machined into the part and third, screwing bolts which have embedded tags in their head into the part (refer to Fig. 6). 

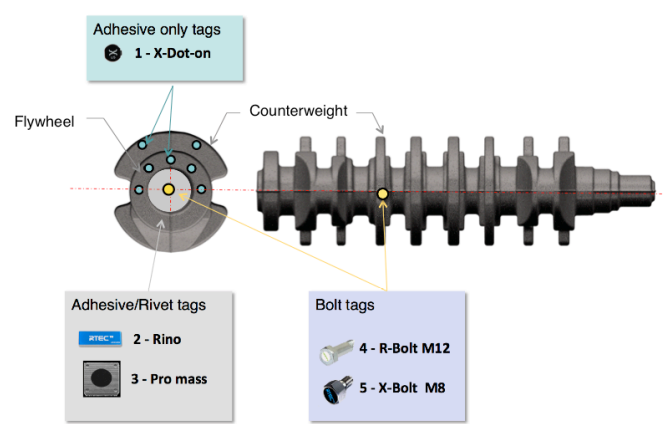

Fig. 6. Crankshaft Locations for UHF Passive Tags classified by Mounting Type.

An inlay comprising of IC Impinj Monza 5 with an embedded antenna was also evaluated. Due to its small size $(2.5 \mathrm{~mm} \times 2.5 \mathrm{~mm} \times 0.4 \mathrm{~mm})$, the tag could be either packaged into smaller bolts (i.e. reusable option) or glued directly onto the crank (i.e. fixed option).

\section{B. UHF Passive RFID tag performance testing}

In practice, measuring the effective reading distance is the key performance index of a tag. The measurement process adopted involves gradually moving the RFID tagged object away from interrogator's antenna reader in a large open space until $50 \%$ or less of signal is received.

Although this approach is simple, it is time consuming. Also, environmental electromagnetic interference reflections may significantly influence the accuracy of the effective reading distance measurement. Undertaking the measurements within an anechoic chamber can eliminate reflections. This method will result in the optimum performance but suffers from not representing the situation encountered within the industrial environment does not constitute a real environment.

The flywheel mating surface and counterweights were tagged with the passive UHF tags previously discussed. A schematic of the experimental set up showing the tag and antenna reader locations is shown in Fig. 7.

For all the measurements, a cast iron V4 crankshaft was used with the antenna reader parameters shown in Table II.

TABLE II. ANTENNA READER PARAMETERS

\begin{tabular}{lc}
\multicolumn{1}{c}{ Parameter } & Description \\
\hline Environment & Laboratory \\
Reader Model & Alien ALR9900 Enterprise Reader \\
Frequency & $886 \mathrm{MHz}-928 \mathrm{MHz}$ (EU-US) \\
Antenna $\quad$ Radiation & Circular polarised \\
Pattern & 1 \\
No. of Antennas & Alien Reader Protocol \\
Reader Protocol & 0.5 seconds \\
Time between Readings & 33dB \\
Antenna Power & \\
\hline \hline
\end{tabular}

The research questions the proposed testing aims to answer are listed as follows:

1) What is the maximum distance range and coverage area?

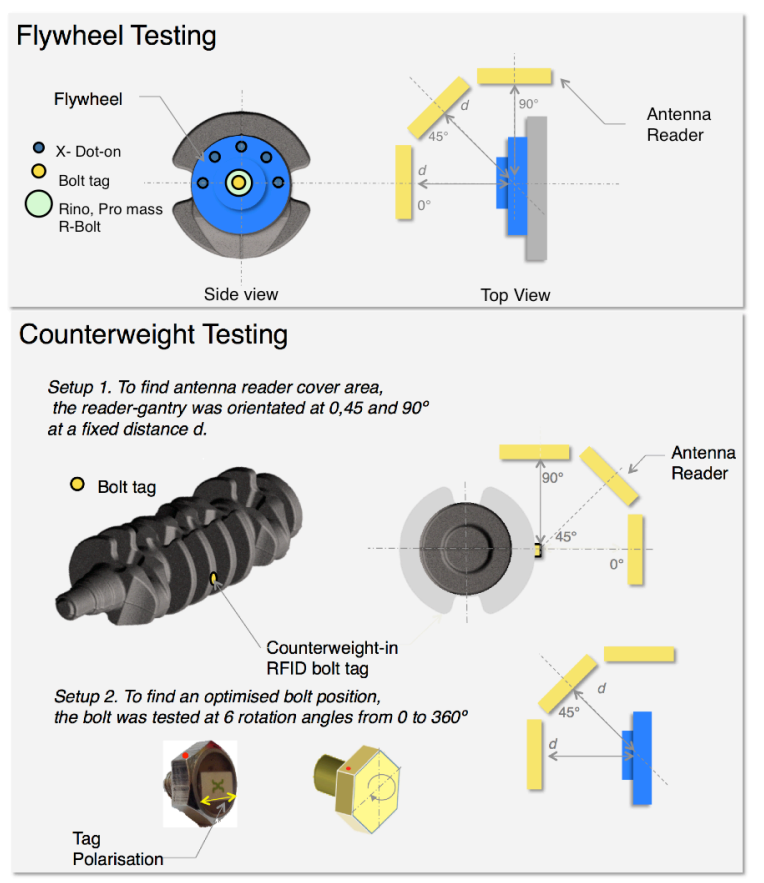

Fig. 7. Experimental Setup showing the locations of passive RFID tags affixed in the crankshaft (flywheel above; counterweight below).

RFID vendors typically report the maximum read range of the tags. However, experience of deploying RFID systems indicates that this claim needs verification and understanding of the deterioration of performance of tags with distance [45]. Acceptance criteria are that a tag should be able to be $\mathrm{read} /$ written $100 \%$ of the time at any distance within the coverage area.

The read range obtainable at different antenna/tag positions is dependent upon the respective radiation pattern. To determine the performance profile of the selected passive RFID tags, the distance $(d)$ between each tagged crankshaft and reader antenna was varied from $0.25 \mathrm{~m}$ to $1.5 \mathrm{~m}$ at $0.25 \mathrm{~m}$ intervals. The reader antenna was placed at three angles, radial to the tagged crank $\left(0^{\circ}\right)$, at $45^{\circ}$ and at $90^{\circ}$ as shown in Fig. 7.

2) RFID Tag Orientation Sensitivity. What is the RFID system performance at various angles?

RFID tag vendors have reported that their tags are readable at all angles with the reader antenna. However, they do not mention the performance variation at various angles with respect to the reader antenna. To determine the orientation sensitivity, tags were orientated at $0^{\circ}, 45^{\circ}, 90^{\circ}$, $180^{\circ}$, and $270^{\circ}$ angles with respect to the reader antenna.

For all the experiments, the Received Signal Strength Indicator (RSSI) was recorded [45]. RSSI is an indication of the power level being received by the antenna. RSSI is a dimensionless parameter provided by most RFID antenna readers and provides range information based on the fact that RF signal emitted or backscattered from a tag attenuates with respect to the distances that the RF signal has travelled.

In addition, tag read rate and tag count patterns also provide information related to the RSSI and thus can be used to estimate the range for reliable performance [46]. In this 
paper, read-rate (i.e. a measure of the \% successful reads / number of attempts) indicates the likelihood that a tag was correctly read by the reader.

\section{RESULTS AND DISCUSSION}

\section{A. Flywheel Tagging}

ProMass and Rhino RFID tags were too large to be attached to the flywheel end plate of the crankshaft, therefore, only the X-Dot-on, X-Bolt and R-bolt were selected. The flywheel end plate was tagged as shown in Fig. 7. As the distance between the reader antenna and the RFID tag was increased, the RSSI value decreased as shown in Fig. 8. This figure also shows that the X-bolt is readable up to $1.4 \mathrm{~m}$ (based upon the distance at which the RSSI falls below a threshold value of 650 ), which is $60 \%$ the maximum distance stated in the vendor's datasheet of $2 \mathrm{~m}$. The difference could due to the environmental effects (e.g. metal, $\mathrm{RF}$ interference) or differences in the supplier testing environments and the laboratory used in the research outlined in this paper.

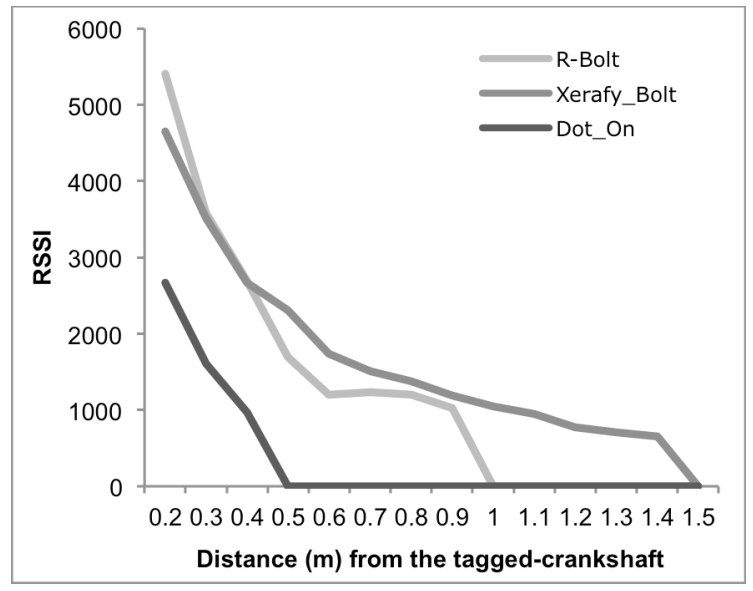

Fig. 8. Comparison between medium-sized tags affixed to the flywheel centre.

The $X$-Dot-On tag is the smallest (e.g. ø $6 \times 2.5(+/-0.2)$ $\mathrm{mm})$ used in the tests. With the reader antenna fitted to the gantry arm, the distance between the crankshaft and the reader is approximately $30 \mathrm{~cm}$. Since the read range of the $X$ Dot-On tag is approximately $40 \mathrm{~cm}$, this tag can be used as a tagging option for the crankshaft when attached to the flywheel end. Depending on the sequencing of different manufacturing operations, the crankshaft orientation with respect to the reader antenna can vary. Since, the $X$-Dot-On tag performance was degraded, i.e. RSSI reduced from 1850 at $0^{\circ}$ to 1300 at $45^{\circ}$ degrees when the tagged crankshaft was oriented perpendicular to the antenna (see Fig. 7). For maximum tag performance, the reader antenna position on the gantry should be chosen directly aligned to the bolt's horizontal polarisation i.e. at an angle of $90^{\circ}$ as shown in Fig. 7.

The reading performance for all the tags tested is summarised in Table III.
TABLe III. ReAding PeRformance For UHF Passive RFID TagS TESTED ON CRANKSHAFT

\begin{tabular}{lcc}
\hline \hline $\begin{array}{c}\text { UHF Passive } \\
\text { Tag }\end{array}$ & Crankshaft Locations & $\begin{array}{c}\text { Reading range at } \\
0^{\circ}(\mathrm{m})\end{array}$ \\
\hline X-Dot-on & Counterweight & 0.5 \\
X-Dot-on & Flywheel & 0.5 \\
Rino & Flywheel & 1.5 \\
Pro mass & Flywheel & 1.2 \\
R-Bolt M12 & Counterweight & 0.7 \\
R-Bolt M12 & Flywheel & 0.9 \\
X-Bolt M8 & Counterweight & 1.4 \\
X-Bolt M8 & Flywheel & 1.5 \\
\hline
\end{tabular}

\section{B. Counterweight Tagging}

In order to locate a bolt tag on the counterweight of each crankshaft, the counterweight needs to be drilled and tapped with an appropriate thread (i.e. M4 in this case). The tags tested for the counterweight location were X-Bolt and RBolt as they can easily attached to the counterweight via nutrunning technologies thus negating the need for adhesive dispensing and curing operations.

\section{1) Setup 1. Finding the antenna reader cover area}

The selected antenna reader can read/write up to a distance of $40 \mathrm{~cm}$ at all orientation angles. Fig. 9 shows the mean of the RSSI values for the crank counterweight tagged with the X-Bolt for a set of five iterations.

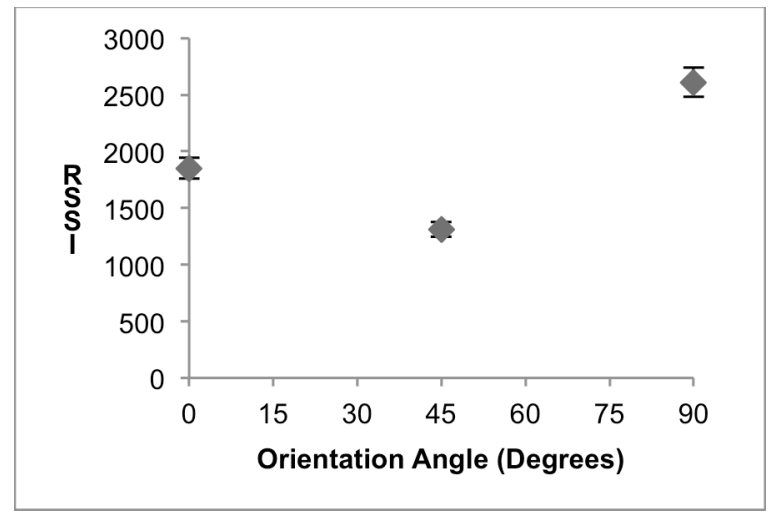

Fig. 9. Reader Antenna at $25 \mathrm{~cm}$ and vertical tag polarisation. The maximum RSSI values were obtained when the tag was at $90^{\circ}$ angle in respect to the antenna.

\section{2) Setup 2. Finding an optimised bolt-antenna} configuration.

The antenna reader was oriented at $0^{\circ}, 45^{\circ}$ at $90^{\circ}$ (refer to Fig. 7), it reads at all angles tested with good RSSI as shown in Fig. 10. It is known that RF antennas are sensitive to polarisation and receive and transmit a signal with a particular polarisation. Therefore, it was expected that the horizontally polarised X-bolt tag would receive horizontally polarised signals best. This was confirmed as shown in Fig. 10. In our proposed crankshaft-gantry system, the reader antenna is located above the crank, and for this topology, the bolt tag was readable in both horizontal and vertical polarisations. This gives the end-user flexibility in using a bolt, as the threading position will not affect the reading. 


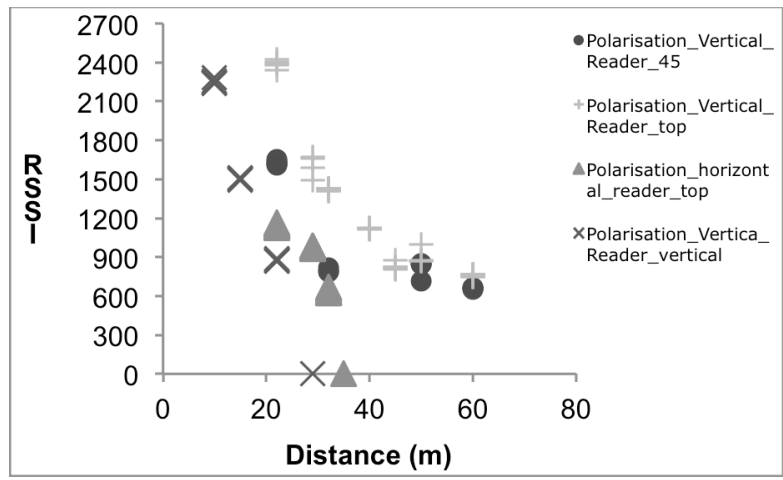

Fig. 10. Reader Antenna at $40 \mathrm{~cm}$ and vertical tag polarisation. The maximum RSSI values were obtained when the tag was at $90^{\circ}$ angle in respect to the antenna.

\section{Cost and benefits of the proposed RFID system}

Complicated cost and benefit structures of RFID system implementations inhibit its worldwide adoption even though it is an identification technology superior to bar code and 2D marking. Hence, both industry and academia have studied RFID costs and benefits[32].

Typically, the costs that constitute an RFID system include: (i) hardware cost (e.g. tags and readers); (ii) middleware costs and (iii) service costs. Table IV shows an estimation of cost factors for the proposed system to monitor crankshafts. The benefits of the RFID system are related to the level on integration and implementation. Representative benefit factors include increased: customer satisfaction; supply chain collaboration; product visibility (e.g. product inventory) and reduced shrinkage and potential for product recall. The estimation of these benefit factors is complex to estimate and also there are limited pilot studies revealing the full set of benefits.

\section{1) Hardware costs}

Although, the price of tags is the major obstacle toward widespread implementation [32], economies of scale may bring the volume cost down, which may encourage adoption (refer to Table I for unit costs for some commercial RFID tags).

The use of reusable tags options such as the smart bolts, incorporated with reverse logistics, may satisfy desired cost targets and represent a reliable flexible way to monitor and track crankshafts throughout their machining and assembly processes. As it was evaluated in this paper, the RFID X-bolt can be screwed to the rough crank either onto: (i) the counterweight or (ii) flywheel and then be removed at the end of machining or assembly to be reused.

Due to the short distance between the crankshaft and the gantry arm, the reading range for most tags is not an issue (refer to Table III). Therefore, low cost ultra small microchips (£0.25 per unit) embedded into, for example a M8 bolt (e.g. £2), would be $60 \%$ cheaper than current commercial available options ( $£ 6$ per tagged bolt).

Together with tag cost, the reader and related communication infrastructure (e.g. GSM module) are often regarded as a capital fixed cost [32]. However, their operation and performance are part of the RFID system's design parameters, which are typically constrained by stakeholders.

\section{2) Middleware cost}

Middleware resides between the enterprise resource planning (ERP) platform and RFID hardware. Middleware software determines how to read/write RFID data by securing reader connectivity, filtering, and aggregation. The middleware cost is usually the cost of software and infrastructure that supports and simplifies RFID-related operations. It is influenced by the complexity of the application and the forms of storing data. Table IV shows a basic set up including webhosting, software-licensing cost per annum.

\section{3) Service costs}

Service costs depend on the implementation context. It typically comprises system design, customisation, configuration, installation and training costs. Other service costs, which may be difficult to quantify, include business process redesign costs such as those incurred if a new process or process are required. For the system discussed in this paper, mounting bolt tags to the cranks would include the following costs, drill bolt thread operation, insert tag operation and re-balancing operation.

Table IV. Costs for the proposed RFID system to monitor crankshafts to 2015

\begin{tabular}{|c|c|c|c|}
\hline Hardware Costs (fixed) & Cost & Qty & Total \\
\hline \multicolumn{4}{|l|}{ RFID hardware } \\
\hline RFID Reader & $£ 1,100$ & 1 & $£ 1,100$ \\
\hline PLC & $£ 326$ & 1 & $£ 326$ \\
\hline Antenna & $£ 87$ & 1 & $£ 87$ \\
\hline GSM Router & $£ 185$ & 1 & $£ 185$ \\
\hline Network Cable & $£ 2$ & 1 & $£ 2$ \\
\hline SD Card & $£ 10$ & 1 & $£ 10$ \\
\hline Enclosure & $£ 289$ & 1 & $£ 289$ \\
\hline Data Logger & $£ 26$ & 1 & $£ 26$ \\
\hline $\begin{array}{l}\text { Total RFID hardware } \\
\text { costs }\end{array}$ & & & $£ 2,024$ \\
\hline \multicolumn{4}{|l|}{ RFID Tags } \\
\hline Bolt Tags (reusable) & $£ 6$ & 1000 & $£ 6,000$ \\
\hline \multicolumn{3}{|l|}{ Total RFID Tag costs } & $£ 6,000$ \\
\hline \multicolumn{4}{|c|}{$\begin{array}{l}\begin{array}{c}\text { Middleware } \\
\text { annum }\end{array} \\
\text { Costs (variable) }\end{array}$} \\
\hline \multicolumn{3}{|c|}{ Basic Read/Write Software Cost } & $£ 6,000$ \\
\hline \multicolumn{3}{|c|}{ Web hosting } & $£ 30$ \\
\hline \multicolumn{3}{|l|}{ Total Middleware costs } & $£ 6,030$ \\
\hline \multicolumn{4}{|l|}{ 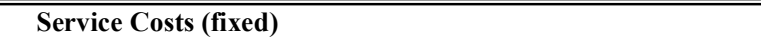 } \\
\hline \multicolumn{3}{|l|}{ Commissioning } & $£ 500$ \\
\hline \multicolumn{3}{|l|}{ Configuration Cost } & $£ 1,000$ \\
\hline \multicolumn{3}{|l|}{ Total Service costs } & $£ 1,500$ \\
\hline \multicolumn{3}{|l|}{ TOTAL COSTS } & $£ 15,554$ \\
\hline
\end{tabular}

Although a final balancing operation to the crank is normally performed, an intermediate balancing operation would be required depending on the process stage at which tags are added and removed from the crank. Balancing is an important operation as any level of unbalance of the crankshaft will cause internal vibration, noise and affect the engine lifetime due to the high rotating speed and fluctuating 
load.

Also the level of integration of the RFID antenna with the gantry arm could range from simply fitting an antenna holding bracket to interfacing to the control software of the gantry to read and write process information useful for recording the full process history.

\section{CONClusions AND FUtURE WORK}

We have proposed a system to make crankshaft smarter by using RFID tags, a digital representation of a crankshaft can be obtained throughout the product's life cycle (e.g. manufacturing, assembly, use). This digital memory can communicate with its environment depending on the level of integration, which in turns depends on end-user requirements.

Using an RFID bolt, crankshafts can be tracked throughout their machining and assembly processes. RFID bolts can be screwed to the rough crank either on the counterweight or flywheel and then be removed at the end of machining or assembly to be reused. However, adding tags to either location in the crankshaft, affects the crank's overall weight and centre of gravity location, so an additional re-balancing operation is required. Leaving the tag fitted in the crank may result in problems during service causing serious damage to the engine. Therefore, a removable, reusable bolt tag option mounted on the flywheel is suggested.

The tested commercially available bolt tags are still expensive for large-scale deployment; therefore research on cheaper solutions for design, on-metal performance for highvolume manufacture systems is needed.

Implementing RFID systems to track automotive parts in industrial automated manufacturing environments is not trivial. Many aspects should be addressed for successful implementations. First, off-the-shelf RFID systems cannot be used "as-is". Tag and portal design and engineering are required to understand the effects between substrate materials (e.g. in this case metal) and the RF signal that will result in the most optimum locations for mounting and positioning tags to cranks and antenna readers.

Second, business process changes are required to capture the real benefit and business value of RFID. For example, rebalancing operations are added or redesigned to facilitate deployment of RFID equipment.

Third, integration to IT and automation control systems such as the gantry robot would improve the reach and better use of the technology and data collected. This integration is not trivial. It is not only about attaching tags or embedding sensors into items in isolation. The data gathered by these tags and sensors needs to be used by supporting software tools. In addition, given the growing value of analytics, new software services should focus on agility rather than the ideal of integration and be able to provide data products that are valuable organisations. Therefore, organisations should be open to evolving data structures rather than relying only on architected data warehouses that provide traditional BI analyses. Then the best techniques (i.e. those that are open, flexible, distributable) in analysing data and generating useful insights into the product, processes, people and the organisation should be employed to improve the whole organisation (e.g. more efficient equipment, manufacturing operations, work practices supply chain).

Fourth, initiatives that develop "test factories" need to be led by business people and not only by technologists. This is because even though the RFID technology may be "fit for purpose" from an operations and manufacturing perspective, it requires that management leaders embrace the ideas and benefits and facilitate the system's success.

\section{ACKNOWLEDGEMENTS}

The authors wish to express their gratitude to the industrial and academic collaborators of the INTELLICO (Intelligent embedded components for enhanced supply chain observability and traceability) project. The TSB Grant award TP No. 14218-87248 supported this work financially.

Also, we thank Xerafy and R-Tech who provided RFID tags and very insightful comments.

\section{REFERENCES}

[1] H. Kagermann, W. Wahlster, and J. Helbig, "Recommendations for implementing the strategic initiative INDUSTRIE 4.0 Final report of the Industrie 4.0 Working Group," 2013.

[2] J. Davis, T. Edgar, J. Porter, J. Bernaden, and M. Sarli, "Smart manufacturing, manufacturing intelligence and demand-dynamic performance," Computers \& Chemical Engineering, vol. 47, pp. 145156, 2012.

[3] P. C. Evans and M. Annunziata, "Industrial Internet: Pushing the Boundaries of Minds and Machines," General Electric 2013.

[4] E. Widl, P. Palensky, P. Siano, and C. Rehtanz, "Guest Editorial Modeling, Simulation, and Application of Cyber-Physical Energy Systems," Industrial Informatics, IEEE Transactions on, vol. 10, pp. 2244-2246, 2014.

[5] R. Rajkumar, I. Lee, L. Sha, and J. Stankovic, "Cyber-physical systems: The next computing revolution," in 47th ACM/IEEE Design Automation Conference (DAC), Anaheim, CA, 2010, pp. 731-736.

[6] J. Fries, S. Dubina, and T. Hapla, "Monitoring of Crankshaft Machining," in Advance Research in Scientific Areas (ARSA), 2012, pp. 1789-1793.

[7] C. Moss, S. Chakrabarti, and D. W. Scott, "Parts quality management: Direct part marking of data matrix symbol for mission assurance," in Aerospace Conference, Big Sky, MT, 2013, pp. 1-12.

[8] ISO/IEC, "Information technology. Automatic identification and data capture techniques. Guidelines for direct part marking (DPM). PD ISO/IEC TR 24720:2008," ed: British Standards Institution, 2012.

[9] "The 2D Data Matrix Barcode," Computing \& Control Engineering Journal, vol. 16, pp. 39-39, 2006.

[10] A. I. A. Group, "Parts Identification \& Tracking Application Standard. B-4," ed: AIAG, 2003.

[11] K. M. Kelly, "Seeing quality: cameras and readable ID marks are helping manufacturers improve their products so that recalls can be minimized. (ISRA Vision Systems Inc. provides direct part mark identification technology for automobile industry)," Automotive Design \& Production, vol. 118, pp. 56-56, 2006.

[12] M. John, "BMW first to adopt data matrix for engine "track and trace"," Assembly Automation, vol. 25, pp. 15-18, 2005.

[13] R. Barron, "Bar coding for fuel injector performance data," US Patent, 1997.

[14] H. J. Alsford, K. Heaslewood, and M. Leese, "Method of providing trim data for a fuel injection," US Patent 20120022766, 2012.

[15] K. Kamijo, N. Kamijo, and Z. G. Zhang Gang, "Invisible barcode with optimized error correction," in 15th IEEE International Conference on Image Processing (ICIP), San Diego, CA, 2008, pp. 2036-2039. 
[16] I. Zafar, U. Zakir, and E. A. Edirisinghe, "Real-time multi barcode reader for industrial applications," in Real-Time Image and Video Processing Brussels, Belgium 2010, p. 7724.

[17] E. R. Cybulski, F. D. Dehn, R. C. Francis, P. B. Hogerton, M. C. Kallestad, K. M. Kropp, et al., "Radio frequency identification systems for asset tracking," US Patent 09/992711, 2003.

[18] R. W. Sorenson, E. L. Son, P. E. Wiesner, W. H. Roeder, and M. S. Clott, "Radio frequency identification (RFID) system for a forklift," 2008.

[19] M. Nikkari, T. Bjorninen, L. Sydanheimo, L. Ukkonen, A. Elsherbeni, and M. Kivikoski, "Performance of a passive UHF RFID tag in reflective environment," in Antennas and Propagation Society International Symposium, San Diego, CA, 2008, pp. 1-4.

[20] J. D. Smith and S. G. Pothier, "Load sensing system including RFID tagged fasteners," ed: Google Patents, 2008.

[21] C. Swedberg. (2012) Industrial Companies Use RFID-enabled Washers to Track Heavy Equipment. RFID Journal. Available: http://www.rfidjournal.com/articles/view?9859/

[22] C. Swedberg. (2014) General Motors Factory Installs Smart Bolts in Engine Blocks, Cylinder Heads RFID Journal. Available: http://www.rfidjournal.com/articles/view?11329

[23] T. Diekmann, A. Melski, and M. Schumann, "Data-on-network vs. data-on-tag: Managing data in complex RFID environments," in 40th Annual Hawaii International Conference on System Sciences, Waikoloa, HI, 2007, p. 224a.

[24] A. Melski, L. Thoroe, T. Caus, and M. Schumann, "Beyond EPC Insights from Multiple RFID Case Studies on the Storage of Additional Data on Tag," in International Conference on Wireless Algorithms, Systems and Applications (WASA) Chicago, IL, 2007, pp. 281-286.

[25] Fujitsu, "World's Largest-Capacity 64kByte FRAM Metal Mount RFID Tag," ed: Fujitsu, 2014.

[26] GS1, "GS1 EPC Tag Data Standard 1.6," ed, 2011.

[27] E. W. T. Ngai, T. C. E. Cheng, K. H. Lai, P. Y. F. Chai, Y. S. Choi, and R. K. Y. Sin, "Development of an RFID-based traceability system: Experiences and lessons learned from an aircraft engineering company," Production and Operations Management, vol. 16, pp. 554-568, 2007.

[28] E. W. T. Ngai and A. Gunasekaran, "RFID adoption: Issues and challenges," International Journal of Enterprise Information Systems, vol. 5, pp. 1-8, 2009.

[29] N. C. Wu, M. A. Nystrom, T. R. Lin, and H. C. Yu, "Challenges to global RFID adoption," Technovation, vol. 26, pp. 1317-1323, 2006.

[30] FAST. (2015, February). Available: http://www.fastcompliance.co.uk/

[31] S. Holloway. (2006, June) RFID: An Introduction. Available: https://msdn.microsoft.com/en-us/library/aa479355.aspx

[32] S. Baysan and A. Ustundag, "The Cost-Benefit Models for RFID Investments," A. Ustundag, Ed., ed: Springer London, 2013, pp. 1322.

[33] R. Bunduchi, C. Weisshaar, and A. U. Smart, "Mapping the benefits and costs associated with process innovation: The case of RFID adoption," Technovation, vol. 31, pp. 505-521, 2011.

[34] T.-J. Fan, X.-Y. Chang, C.-H. Gu, J.-J. Yi, and S. Deng, "Benefits of RFID technology for reducing inventory shrinkage," International Journal of Production Economics, vol. 147, pp. 659-665, 2014.

[35] J. J. Roh, A. Kunnathur, and M. Tarafdar, "Classification of RFID adoption: An expected benefits approach," Information \& Management, vol. 46, pp. 357-363, 2009.

[36] F. T. Patrick Schmitt Elgar Fleisch, "Adoption and Diffusion of RFID Technology in the Automotive Industry," Auto-ID Labs, Zurich, Switzerland2007.

[37] A. J. Mercer, R. K. James, G. Bennett, P. Patel, C. Johnston, and J. Cai, "RFID testing and evaluation for an RF-harsh environment," in RFID-Technologies and Applications (RFID-TA), 2011 IEEE International Conference on, 2011, pp. 95-102.

[38] "UHF vs. HF RFID:

New Insight on the Old Debate," Intermec Techonlogies Corporation2007.

[39] M. Roberti. (2006) The Great RFID Debate: HF or UHF? RFID Journal. Available: http://www.rfidjournal.com/articles/view?2217

[40] Tashi, M. S. Hasan, and Y. Hongnian, "Design and simulation of UHF RFID tag antennas and performance evaluation in presence of a metallic surface," in Software, Knowledge Information, Industrial
Management and Applications (SKIMA), 2011 5th International Conference on, 2011, pp. 1-5.

[41] Axemtec. XR3136 Xerafy Embedded Bolt Tag. Available: http://www.axemtec.com/wp-content/uploads/XR3136 XERAFYEMBEDDED-BOLT-TAG-UK.pdf

[42] F. Berthiaume, K. Donahue, and J. Rommel, "RFID Tag Selection Report " Rutgers Center for Innovative Ventures of Emerging Technologies RFID Tag Source2011.

[43] K. Koski, E. Koski, L. Ukkonen, L. Sydanheimo, T. Bjorninen, J. Virtanen, et al., "Effects of laboratory-scale IC attachment methods on passive UHF RFID tag performance," in Antennas and Propagation (APSURSI), 2011 IEEE International Symposium on, 2011, pp. 1004-1007.

[44] A. A. Babar, T. Bjorninen, V. A. Bhagavati, L. Sydanheimo, P. Kallio, and L. Ukkonen, "Small and Flexible Metal Mountable Passive UHF RFID Tag on High-Dielectric Polymer-Ceramic Composite Substrate," IEEE Antennas and Wireless Propagation Letters, vol. 11, pp. 1319-1322, 2012.

[45] G. Çaliş, B. Becerik-gerber, A. B. Göktepe, S. Li, and N. Li, "Analysis of the variability of RSSI values for active RFID-based indoor applications," TURKISH JOURNAL OF ENGINEERING AND ENVIRONMENTAL SCIENCES, vol. 37, pp. 186-211, 2013.

[46] S. P. Subramanian, J. Sommer, S. Schmitt, and W. Rosenstiel, "RIL \&\#x2014; reliable RFID based indoor localization for pedestrians," in Software, Telecommunications and Computer Networks, 2008. SoftCOM 2008. 16th International Conference on, 2008, pp. 218222. 